\title{
Factors influencing ring closure through olefin metathesis - A perspective
}

\author{
SUBRATA GHOSH*, SARITA GHOSH ${ }^{\text {II }}$ and NILADRI SARKAR \\ Department of Organic Chemistry, Indian Association for the Cultivation of Science, Jadavpur, \\ Kolkata 700032 \\ IPresent address: Jhargram Raj College, Jhargram, Midnapore 721507 \\ e-mail: ocsg@iacs.res.in
}

MS received 2 January 2006; revised 20 April 2006

\begin{abstract}
Success of ring closure reactions of substrates having two terminal alkenes through olefin metathesis depends on a number of factors such as catalysts, nature and size of the rings to be formed and the substituents/functional groups present on the alkenes as well as at the allylic position. This article presents an overview of these influencing factors with illustrative examples.
\end{abstract}

Keywords. Olefin metathesis; molybdenum and ruthenium alkylidines; ring closure; carbocycles; heterocycles.

\section{Introduction}

Construction of rings is one of the fundamental processes in organic synthesis. Of the various strategies available, cyclization is the most straightforward way of obtaining rings. Commonly employed cyclization methods involve reactions of cationic, anionic or radical species. Common rings such as 5-7 membered ones are easily available by these methods. However, formation of medium or large rings by these methods either proceeds with low yields or does not proceed at all due to unfavourable enthalpic and entropic factors. In recent years, olefin metathesis has emerged as a powerful tool for carbon-carbon bond formation and has enabled the synthesis of rings of different sizes.

Mutual exchange of alkylidine groups between two substituted alkenes in the presence of a transition metal catalyst (scheme 1) is termed as olefin metathesis. It is now well established that metathesis proceeds through a $[2+2]$ cycloaddition between an alkene and a metal carbene complex followed by cycloreversion as proposed by Herisson and Chauvin (scheme 2). ${ }^{1}$ The intramolecular olefin metathesis of an $\alpha, \omega$-diolefin leading to cycloalkenes is known as ring-closing metathesis (RCM) (scheme 3). The driving force for this reaction is the release of highly volatile ethylene. The efficiency of RCM depends

\footnotetext{
*For correspondence
}

on to what extent the competing acyclic diene metathesis polymerization (ADMET) (scheme 3 ) can be

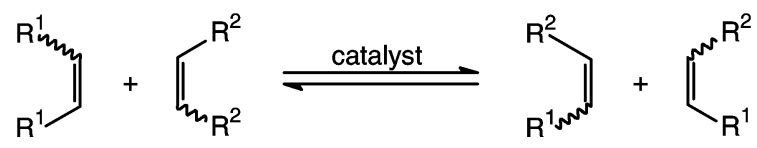

Scheme 1.

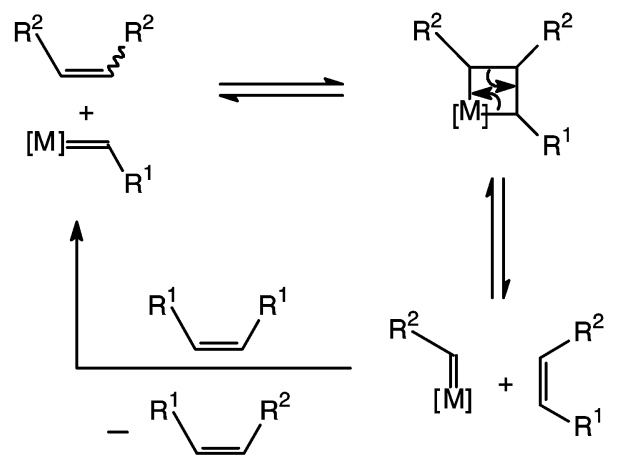

Scheme 2.

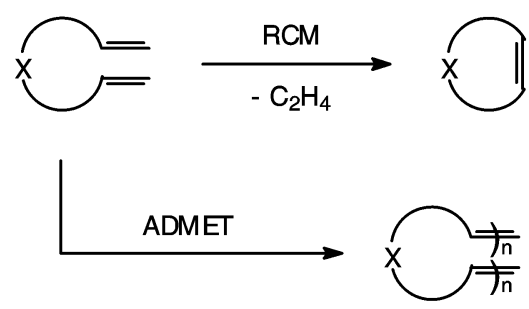

Scheme 3 . 
overcome. Concentration of the substrate helps to reduce ADMET to some extent. However, the success of a ring-closure reaction through olefin metathesis is influenced to a great extent by a number of factors. These include (1) efficiency of the catalyst, (2) nature of the resulting rings, (3) size of the rings to be formed and (4) functional groups/substituents present in the substrate. The past several years have witnessed an explosive growth of the applications of olefin metathesis. A number of excellent accounts ${ }^{2}$ focussing mainly on the application have been published. The prime objective of this account is to focus on the factors that influence RCM with illustrative examples.

\section{Influence of catalyst on RCM}

The classical olefin metathesis catalysts composed of transition metal salts and their complexes with main group alkylating agents (such as $\mathrm{WCl}_{6} / \mathrm{Bu}_{4} \mathrm{Sn}$, $\mathrm{MoO}_{3} / \mathrm{SiO}_{2}, \quad \mathrm{Re}_{2} \mathrm{O}_{7} / \mathrm{N}_{2} \mathrm{O}_{3} \mathrm{Cl}_{2}$ ) were inefficient for RCM. An efficient RCM catalyst ${ }^{3}$ should be a good initiator of metathesis, should react exclusively or at least preferentially with olefins over the other polar groups present in the olefinic substrate and should be stable to air and moisture. The mechanism of olefin metathesis proposed by Herisson and Chauvin (scheme 2) guided the design and development of active catalysts. According to this mechanism, stabilized alkylidine-transition metal complexes should be efficient initiators. In fact, $\mathrm{Fu}$ and Grubbs ${ }^{4}$ first demonstrated that tungsten and molybdenum alkylidines 1a,b and 2a,b, developed by Schrock for polymerization initiator, can induce RCM for the formation of 5-7 membered rings. However, W and Mo have a strong tendency to react with polar groups such as hydroxyls, aldehydes, carboxylic acids etc in addition to olefins. Thus, W and Mo catalysts are highly oxophilic and have poor functional group tolerance. Compared to $\mathrm{W}$ and $\mathrm{Mo}, \mathrm{Ru}$ reacts preferentially with olefins over the polar groups. A systemic investigation by Grubbs and coworkers ${ }^{5}$ led to the discovery of ruthenium carbene complexes of the general formula $\mathbf{3}$ as active catalysts for RCM.

The initiating ability of the catalyst $\mathbf{3}$ depends on the substituent ' $R$ ', while the activity of the catalyst 3 is dependent on the type of ligands $\mathrm{L}^{1}$ and $\mathrm{L}^{2}$. An understanding of the detail steps involved during metathesis enables to understand how the ligands $\mathrm{L}^{1}$ and $\mathrm{L}^{2}$ influence the reactivity of the catalyst. Based on the reactivity trend of a number of catalysts, Grubbs proposed a three-step sequence for metathe- sis (scheme 4): (i) olefin coordination to the metal centre to form the species 4 , (ii) dissociation of one of the ligands $\left(\mathrm{L}^{2}\right)$ to form $\mathbf{5}$, and (iii) formation of the metallocyclobutane $\mathbf{6}$ followed by cycloreversion to the product.

For productive metathesis, the dominant pathway is the dissociation of one of the ligands. Thus, any variation of the ligands or substituent $\mathrm{R}$ that assist ligand dissociation make $\mathbf{3}$ an active catalyst. A bulkier and more strongly electron-donating ligand helps in dissociation of the other ligand as well as stabilize the reactive intermediate 5. For example, a ligand more basic and bulkier than $\mathrm{PPh}_{3}$ increases the stability and reactivity of a catalyst. Thus, $\mathbf{3 b}$ is a more active RCM catalyst than the catalyst $\mathbf{3 a}$. The catalyst $\mathbf{3 c}$ has significantly improved activity over the catalyst $\mathbf{3 b}$ due to its high rate of initiation. The bulk of the $\mathrm{Ph}$ group probably assists ligand (phosphine) dissociation. The catalyst $\mathbf{7}$ having more basic and bulkier N-heterocyclic carbene (NHC) than $\mathrm{PCy}_{3}$, would be expected to be more active than the catalyst $\mathbf{3 c}$, but however does not show any improved activity. However, catalysts $\mathbf{8}$ and $\mathbf{9}$ having
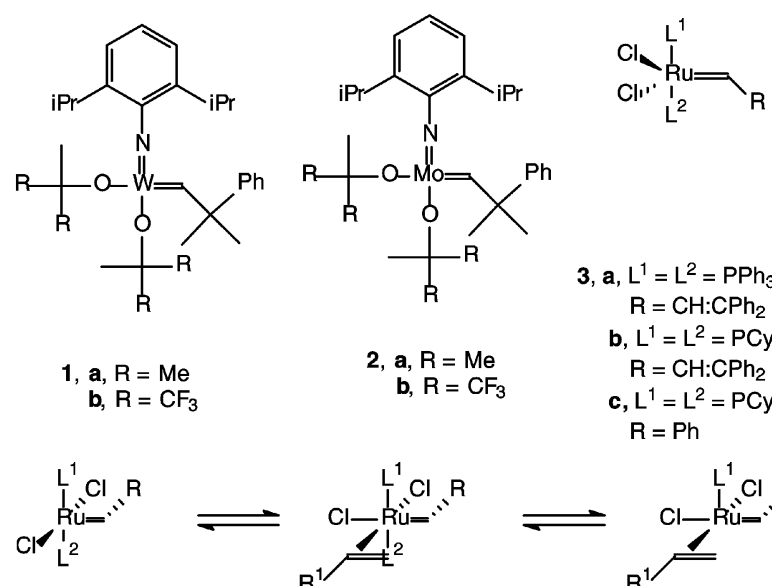

3

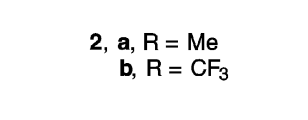

3, a, $\mathrm{L}^{1}=\mathrm{L}^{2}=\mathrm{PPh}_{3}$ $\mathrm{R}=\mathrm{CH}: \mathrm{CPh}_{2}$ b, $\mathrm{L}^{1}=\mathrm{L}^{2}=\mathrm{PCy}_{3}$ $\mathrm{R}=\mathrm{CH}: \mathrm{CPh}_{2}$ c, $\mathrm{L}^{1}=\mathrm{L}^{2}=\mathrm{PCy}_{3}$ $\mathrm{R}=\mathrm{Ph}$
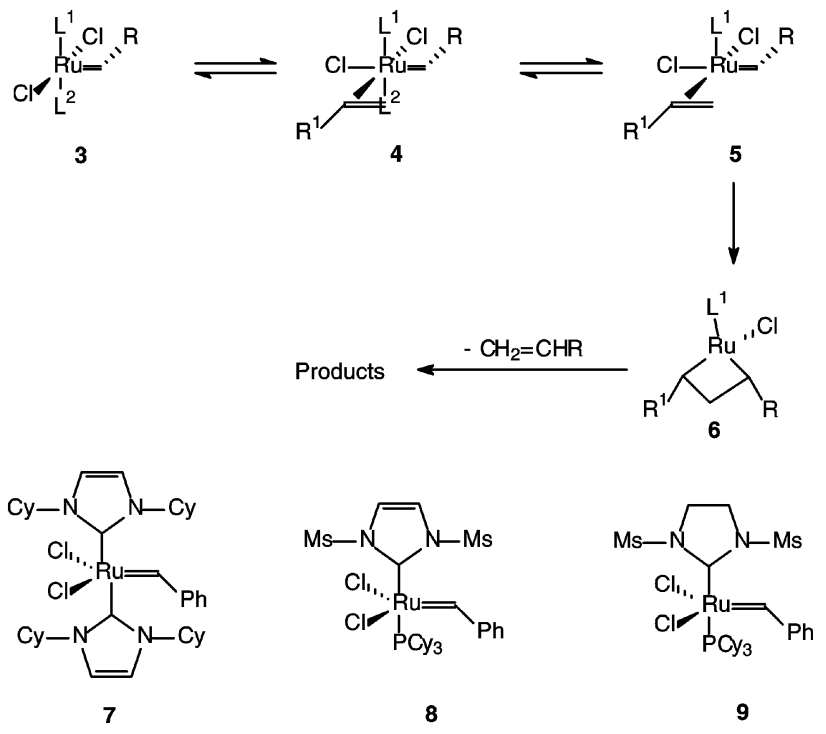

Scheme 4. 
NHC and $\mathrm{PCy}_{3}$ as the ligands $\left(\mathrm{L}^{1}\right.$ and $\mathrm{L}^{2}$ in 3 ) show enhanced metathesis activity. The more strongly electron-donating NHC ligand enhances the dissociation of the more labile phosphine and more efficiently stabilizes the electron-deficient intermediate 5 (scheme 4). This accounts for the increased reactivity of the catalysts 8 and $\mathbf{9}$. The reactivities of $\mathbf{8}$ and $\mathbf{9}$ are superior to that of the catalyst $\mathbf{3 c}$ and are comparable to the reactivity of the Schrock catalyst 2b but with greater functional group tolerance. However, easy accessibility and low cost of the catalyst 3c make it the most popular catalyst and it has been widely used for various synthetic purposes. The following examples illustrate how RCM of diolefins is influenced by these catalysts.

The dienes $\mathbf{1 0}$ and $\mathbf{1 2}$ undergo ring closure very efficiently ${ }^{6}$ using the Mo catalyst $\mathbf{2 b}$ to give the tetrasubstituted cyclopentene $\mathbf{1 1}$ and cyclohexene derivative $\mathbf{1 3}$ in $93 \%$ and $61 \%$ yields respectively (scheme 5). However, RCM of the dienes $\mathbf{1 0}$ and $\mathbf{1 2}$ does not proceed at all with Grubbs' catalyst 3c. Similarly, the diene 14 undergoes ring closure ${ }^{7}$ with 2 mol\% of the Mo catalyst $\mathbf{2 b}$ to give the cyclopentene $\mathbf{1 5}$ quantitatively, while the same cyclization with Ru catalyst $3 \mathbf{c}$ proceeds with lower yield. ${ }^{2 b}$ These examples illustrate the efficiency of the Mo catalyst to induce metathesis of substituted olefins.

$\mathrm{RCM}$ of the sulphur containing diene $\mathbf{1 6}$ proceeds $^{8}$ smoothly in the presence of the catalyst $\mathbf{2 b}$ but fails in the presence of the $\mathrm{Ru}$ carbene $3 \mathrm{c}$ (scheme 6). The difference in reactivities of the Mo and Ru carbenes for effecting the cyclisation of $\mathbf{1 6}$ has been

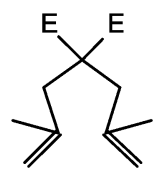

10

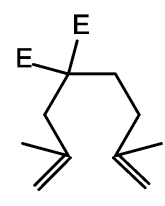

12

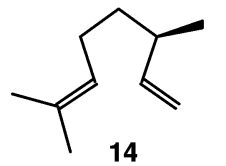

Cat. 3b (2 mol\%)
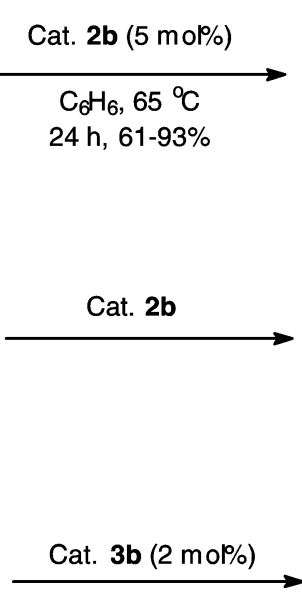

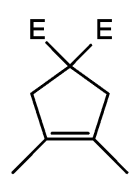

11

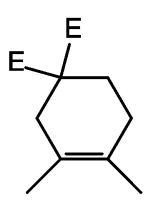

13

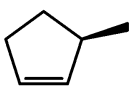

15 explained by 'mismatch' of the 'hard' $\mathrm{Mo}^{\mathrm{vi}}$ centre with 'soft' sulphur or phosphine functionalities. For $\mathrm{RCM}$ of dienes with vinyl ether as one of the alkene units, Mo catalyst $\mathbf{2 b}$ is required. Thus, dienes $\mathbf{1 8}$ undergo smooth ring closure ${ }^{9}$ with the Mo carbene 2b to produce the cyclic vinyl ethers $\mathbf{1 9}$ in good to excellent yields (scheme 7). On the contrary, the Ru catalyst 3c proved to be totally ineffective for the cyclization of enol ethers. This failure of the $\mathrm{Ru}$ catalyst has been attributed to the formation of the inert carbenes from rapid reaction of the vinyl ethers with $\mathrm{Ru}$ catalysts. However, Sturino and Wong ${ }^{10}$ have demonstrated that vinyl ethers can also be cyclised with Grubbs' catalyst 3c as illustrated by conversion of $\mathbf{2 0}$ to $\mathbf{2 1}$ (scheme 7).

The superiority of the catalyst $\mathbf{2} \mathbf{b}$ is further demonstrated $^{11}$ by smooth ring closure of the diene 22 to form the strained medium-sized ring $\mathbf{2 3}$ (scheme 8). Ring closure fails completely with the Ru catalyst $\mathbf{3 c}$.

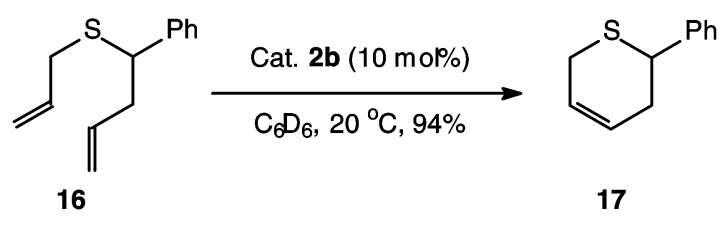

Scheme 6.

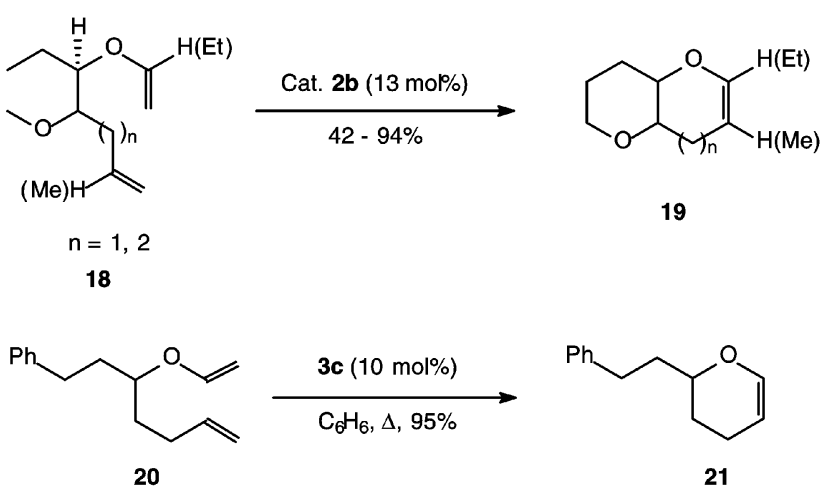

Scheme 7.
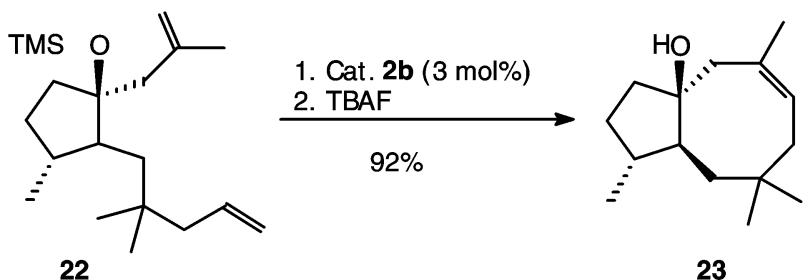

23

Scheme 5.

Scheme 8. 
Comparison of the reactivity of the Mo catalyst $\mathbf{2 b}$ with those of the $\mathrm{Ru}$ catalysts $\mathbf{3 c}$ and $\mathbf{8}$ shows that the $\mathrm{Ru}$ catalyst $\mathbf{8}$ has reactivity comparable with the Mo catalyst $\mathbf{2 b}$, while the Ru catalyst $\mathbf{3 c}$ is much less reactive than $\mathbf{2 b}$ and $\mathbf{8}$. RCM of the diene $\mathbf{2 4}$ was complete $^{12}$ in $1 \mathrm{~h}$ with Schrock's catalyst to afford $\mathbf{2 5}$ in $92 \%$ yield (scheme 9). With the Ru catalyst 3c, cyclization required longer reaction time and high concentration of the catalyst to give $\mathbf{2 5}$ in poor yield (32\%). However, with the Ru complex $\mathbf{8}$, the reaction was complete in $2 \mathrm{~h}$ with $89 \%$ yield of the cyclised product.

Owing to its steric crowding, the Ru catalyst $\mathbf{3 b}$ is able to cyclise only one diastereoisomer in the diene mixture $\mathbf{2 6}$ to afford the cyclohexene derivative $\mathbf{2 7}$ while the Mo catalyst $\mathbf{2 b}$ indiscriminately cyclises both the diastereoisomers of $\mathbf{2 6}$ to afford a mixture of the products $\mathbf{2 7}$ and $\mathbf{2 8}$ (scheme 10). ${ }^{13}$

The greater reactivity of the Ru catalyst 9 over the $\mathrm{Ru}$ catalyst 3c towards RCM can be demonstrated by the recently reported ${ }^{14}$ total synthesis of heliannuol D using RCM as the key step (scheme 11). Attempted RCM of the diene $\mathbf{2 9}$ using Grubbs' catalyst $\mathbf{3 c}$ at room temperature fails to form the oxepene $\mathbf{3 0}$. At elevated temperature $\left(50^{\circ} \mathrm{C}\right)$ only dimerisation is observed. However, RCM of the diene 29 proceeds smoothly at room temperature (RT) with catalyst 9 to produce the desired oxepene 30 in $94 \%$ yield.

Recently, we also observed ${ }^{15}$ that RCM of the diene 31 with Ru-catalyst 3c at RT fails to produce any cyclised product $\mathbf{3 2}$ but at elevated temperature only

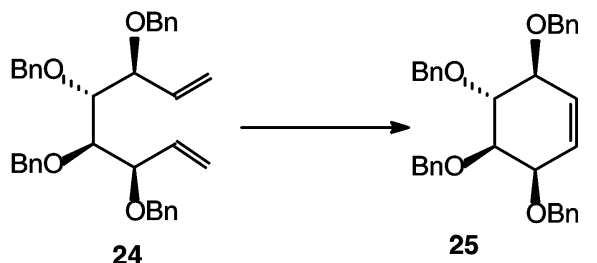

Cat. 2b, 1h, $92 \%$

Cat. 3c, 60h, 32\%

Cat. 8, 2h, $89 \%$

Scheme 9.
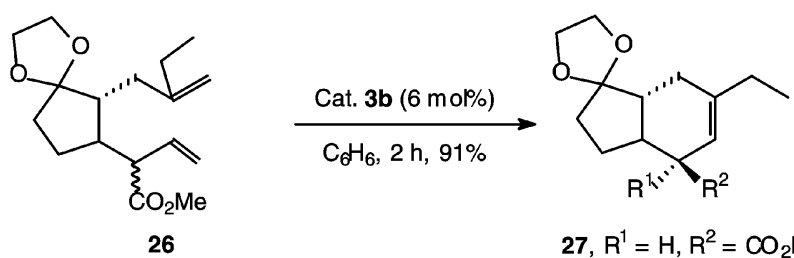

27, $\mathrm{R}^{1}=\mathrm{H}, \mathrm{R}^{2}=\mathrm{CO}_{2} \mathrm{Me}$ 28, $\mathrm{R}^{1}=\mathrm{CO}_{2} \mathrm{Me}, \mathrm{R}^{2}=\mathrm{H}$ a dimer is formed. With the catalyst $\mathbf{9}, \mathrm{RCM}$ of the diene 31 is smooth at RT and in $8 \mathrm{~h}$ produces the cycloheptenol 32 in greater than $90 \%$ yield (scheme 12).

Unsaturated esters are not considered as good substrates for RCM. In spite of this, RCM of the diene $\mathbf{3 3}$ with the catalyst $\mathbf{3 b}$ affords the cyclic product $\mathbf{3 4}$ (scheme 13$)^{16}$ in very good yield when carried out at elevated temperature. $\alpha, \beta$-Unsaturated ketones have not generally been used in RCM, possibly due to the electron-deficient character of the double bond which reduces the metathesis efficiency. However, Paquette and coworkers have recently shown that with the catalyst 9, RCM of the dienone 35 proceeds ${ }^{17}$ smoothly to produce the cyclooctenone derivative $\mathbf{3 6}$ in $90 \%$ yield (scheme 13).

Remarkable catalytic specificity has been obser$\mathrm{ved}^{18}$ during RCM of the enantiopure triene 37. While the Ru catalyst $\mathbf{3 c}$ affords the anti product $\mathbf{3 8}$,

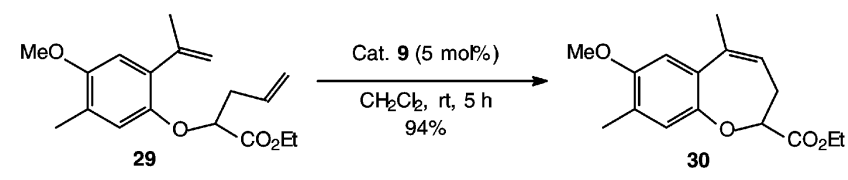

Scheme 11.

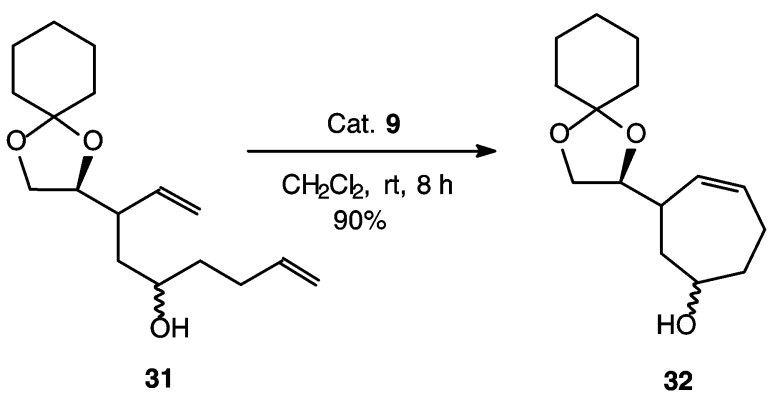

Scheme 12.<smiles>C=CCN1C(=O)[C@H](Cc2ccccc2)[C@@H](OCc2ccccc2)[C@H](OCc2ccccc2)[C@]1(/C=C/C(C)=O)Cc1ccccc1</smiles><smiles>C=CC(=O)CCc1cocc1[C@@H](C=C)O[Mg]O[Mg]</smiles>

Scheme 13. 


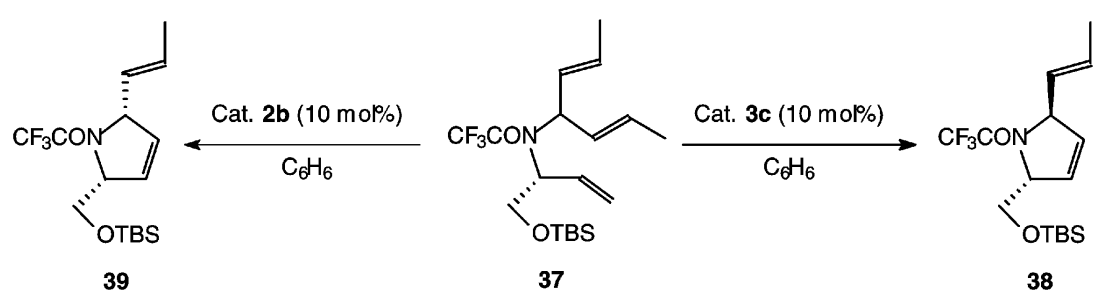

Scheme 14.

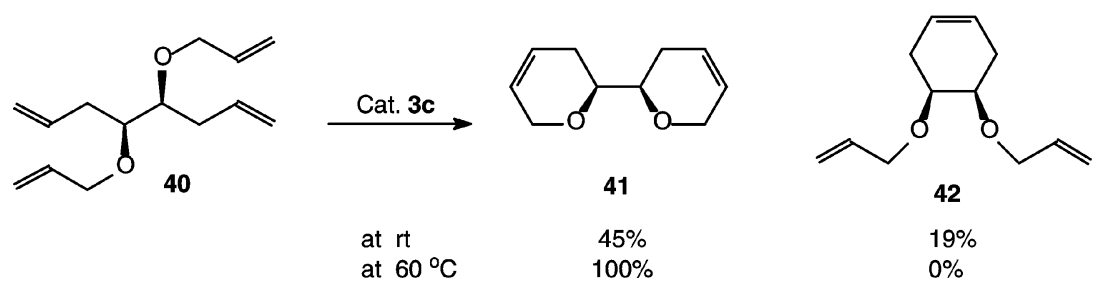

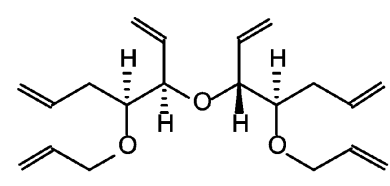

43

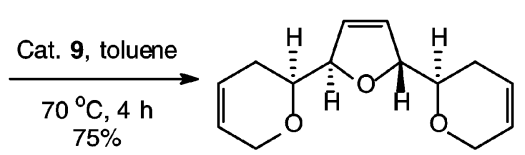

44

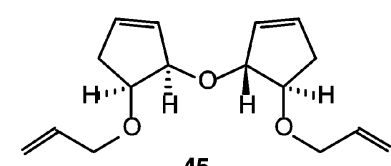

45

Scheme 15.

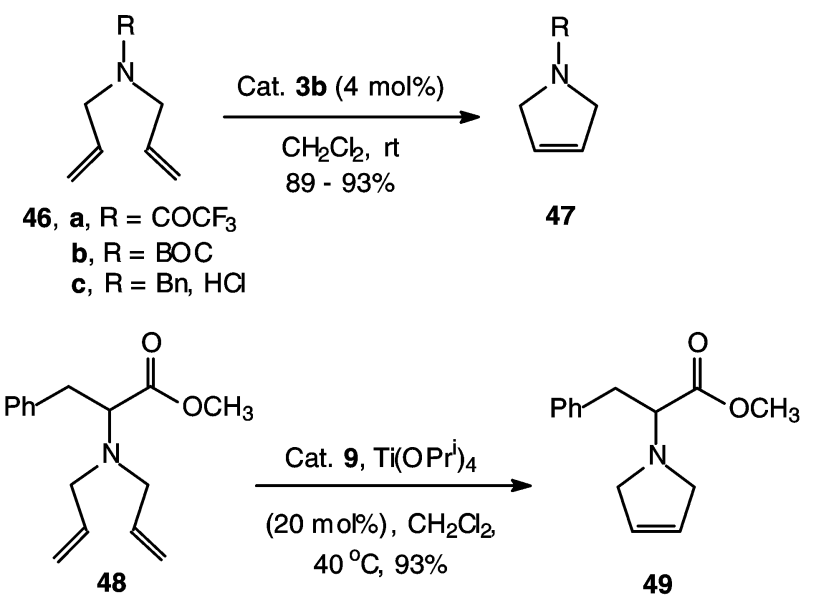

Scheme 16.

the Mo catalyst $\mathbf{2 b}$ gives the syn product $\mathbf{3 9}$ exclusively (scheme 14). The observed specifity is attributed to the different spatial arrangement of the respective ligands in each complex during cyclization.

\section{Nature of the resulting rings (carbocycle or heterocycle)}

Olefin metathesis has been efficiently employed for the construction of both carbocycles as well as oxygen heterocycles. However, when there is a possibility of the formation of carbocycles as well as oxygen heterocycles of the same size, it is the latter one which is favoured (scheme 15). For example, the tetraene 40 in the presence of Grubbs' catalyst $\mathbf{3 c}$ at $\mathrm{RT}$ for $1 \mathrm{~h}$ produces the bicyclic ether $\mathbf{4 1}$ in $45 \%$ yield with $19 \%$ yield of the carbocycle $\mathbf{4 2}$. The same reaction, when carried out at $60^{\circ} \mathrm{C}$, forms the bicyclic ether $\mathbf{4 1}$ as the only product. ${ }^{19}$ Similarly, cyclization of the tetraene $\mathbf{4 3}$ with Grubbs' catalyst 9 leads to the exclusive formation of the tricyclic ether $\mathbf{4 4}$ without any trace of the carbocycle $\mathbf{4 5} .^{20}$

The formation of nitrogen heterocycles by RCM of dienes containing nitrogen atoms between two alkene units does not proceed due to the basicity and nucleophilicity of the $\mathrm{N}$ atoms which deactivate the catalyst through coordination with the metal centre of the catalyst. ${ }^{21}$ In such cases, the substrates have to be deactivated either by conversion to the amides, carbamates, or sulphonamides or by protonation. Grubbs and coworkers ${ }^{22}$ demonstrated that N-trifluoroacetyl diene 46a underwent smooth RCM with Mo catalyst $\mathbf{2 b}$ to afford the dihydropyrrole $\mathbf{4 7 a}$. These RCM reactions can also be catalyzed by the $\mathrm{Ru}$ catalyst $\mathbf{3 b}$ (scheme 16). Recently, it has been demonstrated $^{23}$ that Lewis acids such as $\left[\mathrm{Ti}(\mathrm{OPr})_{4}\right]$ facilitate RCM of the diallylamine $\mathbf{4 8}$ using the $\mathrm{Ru}$ catalyst 9 to afford the pyrrolidine derivative 49 . 


\section{Size of the ring to be formed}

Reactivity in RCM of dienes is influenced to a great extent by the size of the rings to be formed. This is illustrated by the cyclization of the dienes 50a-c. The diene 50a undergoes smooth ring closure in $24 \mathrm{~h}$ at RT to form the cyclopentenol 51a with Grubbs' catalyst 3c in $83 \%$ yield. Under similar conditions, the diene 50b produces the cyclohexenol 51b quantitatively in only $4 \mathrm{~h}$ (scheme 17). However, the diene 50c fails to produce the cycloheptenol 51c even on prolonged reaction at RT as well as at elevated temperatures. Thus, as ring size increases it becomes difficult to construct rings through cyclization.

Reactivity in cyclization reaction is influenced by the activation energy in the transition state and the probability of end-to-end encounters (entropy). The activation energy is thought to reflect the strain energy of the ring to be formed and is markedly dependent on ring size, as shown by strain energy data
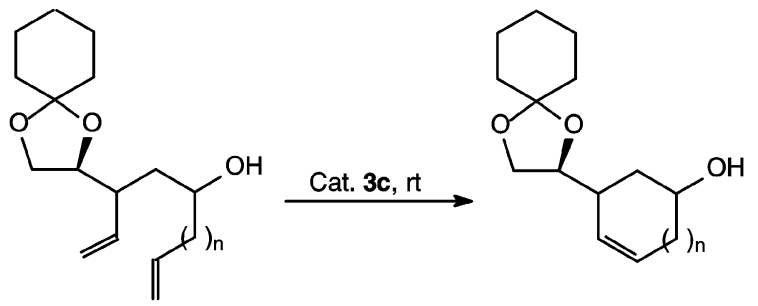

51

50, a, $\mathrm{n}=0$

b, $n=1$

c, $n=2$

$83 \%$ in $24 \mathrm{~h}$ $100 \%$ in $4 \mathrm{~h}$ $0 \%$ on heating

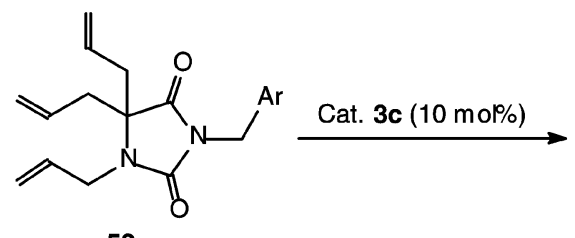

52

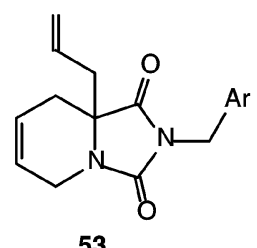

53

Scheme 17.

Table 1. Strain energy of various rings.

\begin{tabular}{lc}
\hline Ring size & $\begin{array}{c}\text { Strain energy } \\
\left(\mathrm{kcal} \mathrm{mol}^{-1}\right)\end{array}$ \\
\hline 5 & $6 \cdot 5$ \\
6 & $0 \cdot 0$ \\
7 & $6 \cdot 3$ \\
8 & $9 \cdot 6$ \\
9 & $12 \cdot 6$ \\
10 & $12 \cdot 0$ \\
11 & $11 \cdot 0$ \\
\hline
\end{tabular}

(table 1). ${ }^{24}$ From these data it is clear why the 6membered ring 50b is easily formed. Although 5and 7-membered rings have comparable strain energies (higher than 6-membered), it is the entropic factor that prohibits cyclisation of 50c to form the sevenmembered ring 51c.

Formation of medium size rings through RCM requires several features to be installed in the substrate and provide some sort of conformational constraint. This conformationally predisposes the dienes for ring closure. These constraints are achieved either by using a pre-existing ring, i.e. cyclic conformational constraint, or acyclic conformational constraint.

\subsection{Pre-existing ring as cyclic conformational constraint}

There are several reports where aromatic rings have been used for cyclic conformational constraint. For example, RCM of the diene 28 using Grubbs' catalyst 9 produces seven-membered cyclic ether 29 in excellent yield. Similarly, the diene $\mathbf{5 4}$ is ring closed using the catalyst $\mathbf{8}$ to form the oxepene $\mathbf{5 5}$ (scheme 18). ${ }^{25}$

Cyclic ethers also provide very good conformational constraint. For example, the dienes $\mathbf{5 6}$ easily cyclise with Grubbs' catalyst 3c to form seven- to nine-membered cyclic ethers $\mathbf{5 7}$ in excellent yields. ${ }^{26}$ Ring closure of the dienes $\mathbf{5 8}$ is achieved with the Mo catalyst $\mathbf{2 b}$ to form eight- and nine-membered cyclic ethers 59 (scheme 19).

Derivatives of sugars provide excellent conformational constraint. For example, cyclization ${ }^{27}$ of dienes 60 and 62 can be achieved with Grubbs' catalyst $3 c$ to form seven and nine-membered cyclic ethers 61 and 63 respectively, in excellent yields (scheme 20). Pre-existing carbocycles also facilitate formation of cycloheptenes ${ }^{28}$ through RCM. In an approach toward the synthesis of guanacastepenes, Mehta and coworkers $^{28 a}$ demonstrated that seven-membered rings could be constructed in very high yields on pre-existing five-membered carbocycle 64 to afford the hydroazulene derivative $\mathbf{6 5}$ (scheme 21). Similarly,
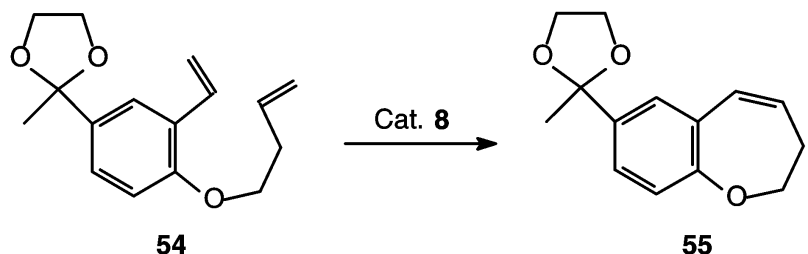

55

Scheme 18. 

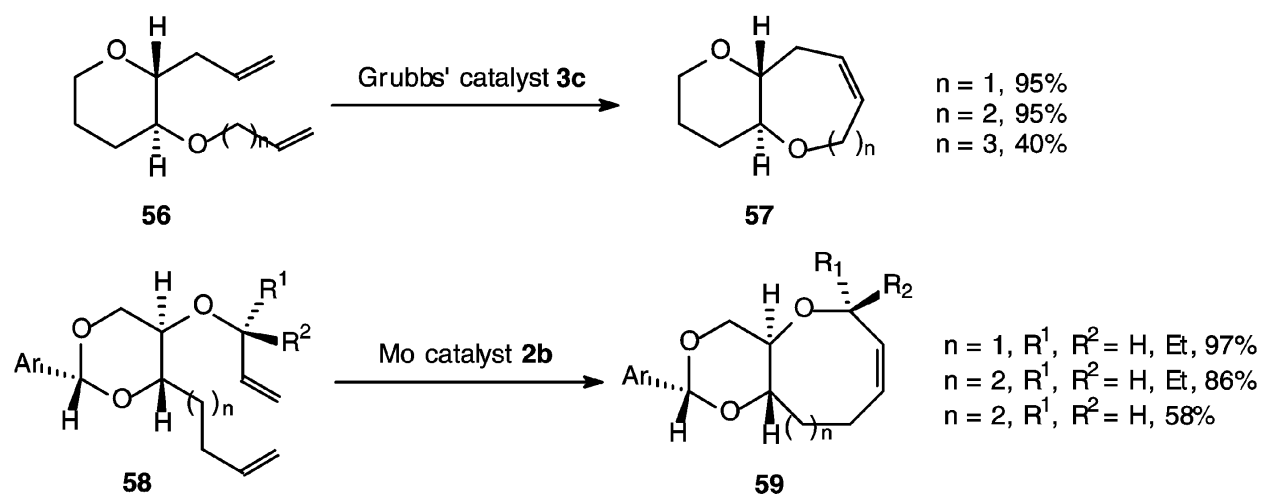

Scheme 19.<smiles>C=CCO[C@H]1C(OC)O[C@@H]2CO[C@H](c3ccccc3)O[C@]21C</smiles>

60, $\mathrm{n}=1$ 62, $n=3$<smiles>CO[C@H]1O[C@H]2CO[C@@H](c3ccccc3)O[C@H]2[C@H]2CC=CCC[C@H]12</smiles>

$61, \mathrm{n}=1,87 \%$ 63, $n=3,74 \%$

Scheme 20.<smiles>C=CCCC1=CC(=O)C(C(C)C)[C@]1(C)CC=C</smiles>

64<smiles>C=CCCC1=C(C)C(=O)C[C@H](C(=C)C)C1(C)CC=C</smiles>

66

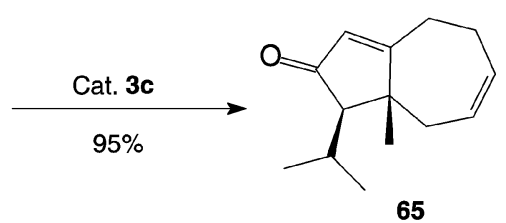

65

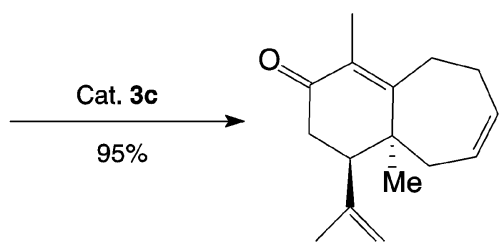

67
Scheme 21.

seven-membered carbocycle 67 can be constructed in excellent yield on a six-membered carbocycle $\mathbf{6 6}^{28 \mathrm{~b}}$ (scheme 21).

Stereochemistry at the ring fusion of the bicycles to be formed has profound influence on the rate of RCM reaction. Grubbs et $a l^{29}$ demonstrated that trans ring fusion facilitates the synthesis of the [6.4.0] system. Thus, the trans-diene $\mathbf{6 8}$ produces $60-75 \%$ of the cyclised product 69 whereas the corresponding cis-diene $\mathbf{7 0}$ affords only $20-33 \%$ of the cyclic ether 71 (scheme 22).

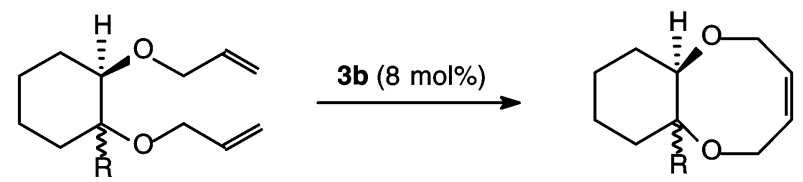

68, $R=\beta-H$

70, $R=\alpha-H$

$69, \mathrm{R}=\beta-\mathrm{H}$ 71, $R=\alpha-H$

Scheme 22.<smiles>C=CCCC[C@@]1(O)[C@H](OC)O[C@H]2CO[C@H](c3ccccc3)O[C@H]2[C@H]1CC=C</smiles>

Scheme 23.

Synthesis of eight-membered carbocyclic rings is of considerable importance because of the presence of this ring in many biologically active natural products. A large number of methodologies other than cyclization for the synthesis of eight-membered rings have been developed. Olefin metathesis offers an excellent route for achieving synthesis of 8-membered rings. Facile construction of 8 -membered rings has been possible only when the alkene units are present on a pre-existing ring. For example, the diene 72 undergoes smooth ring closure when treated with Grubbs' catalyst 3c to form the cyclooctene derivative 73 in good yield (scheme 23 ). ${ }^{30}$

The importance of a pre-existing ring for the formation of 8-membered ring has been nicely demonstrated by Prunet et al. ${ }^{31}$ The diene $\mathbf{7 4}$ produces the cyclised product $\mathbf{7 5}$ in very poor yield. However, when the two vicinal hydroxyl groups on the chain 
bearing the alkene units are protected as a cyclic acetal, the resulting dioxolane ring in $\mathbf{7 6}$ provides the necessary conformational constraint that facilitates RCM to form the cyclooctene derivative $\mathbf{7 7}$ in excellent yield (scheme 24).

Lactams, ${ }^{32}$ pyrrolidines ${ }^{33}$ and oxazolines ${ }^{34}$ also provide excellent conformational constraints. Seven,
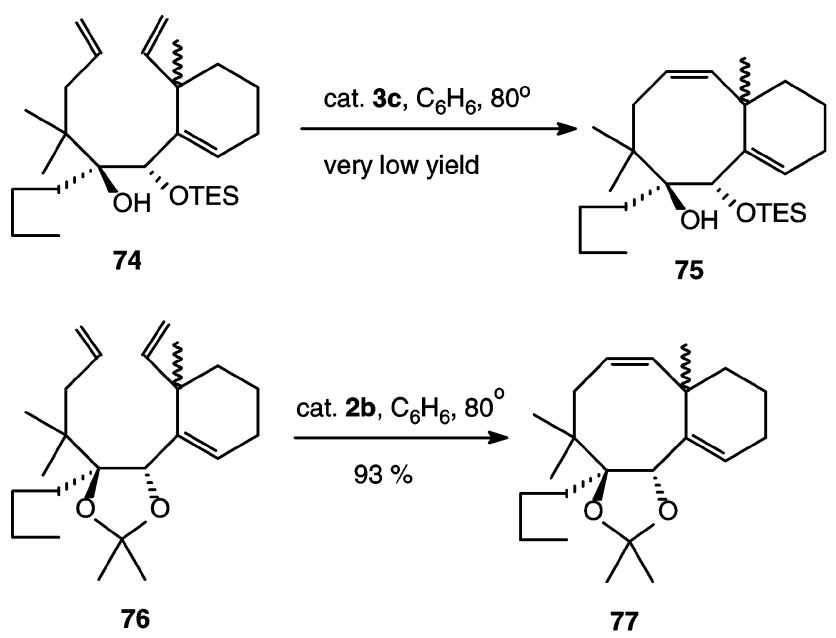

Scheme 24.<smiles>C=CCCC1(CC=C)CCCC(=O)N1CC=C</smiles><smiles>CCC1(C)CCCC(=O)N1CCC(C)C</smiles>

$\mathrm{n}=1,95 \%$ $n=2,83 \%$

78

79

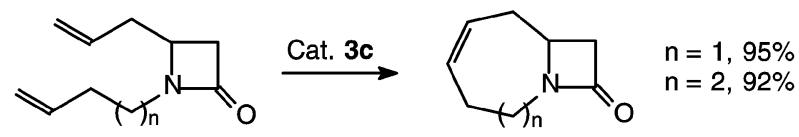
80 81

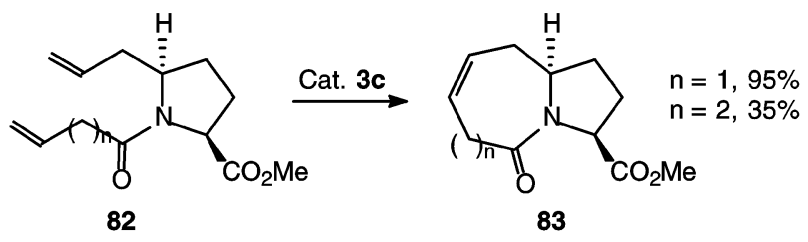
82<smiles>[Z]N(CC=C)C[C@]1([2H])N=C(Br)O[C@]1(C)C=C</smiles><smiles>[Z]N1CC=C[C@H]2OC(Br)=N[C@H]2C1</smiles>

eight and nine-membered rings can be easily annulated on them through RCM of vicinal chains containing terminal alkene units to lead to bicyclic systems (scheme 25).

\subsection{Acyclic conformational constraint}

The Thorpe-Ingold effect of the geminal substituents provides conformational constraint to acyclic $\alpha, \omega$ dienes and facilitates RCM. This is nicely demonstrated ${ }^{35}$ by smooth ring closure of the diene 86 with the Mo catalyst $\mathbf{2 b}$ to form the cycloheptenone $\mathbf{8 7}$ (scheme 26). In contrast, the diene $\mathbf{8 8}$ devoid of geminal substituents fails to produce any cyclised product under identical condition.

Vicinal stereocentres present on acyclic dienes can lead to conformations where olefinic chains are positioned gauch and help in ring closure. A comparison of the reactivity of dienes $\mathbf{8 9}$ and $\mathbf{9 0}$ towards RCM with the catalyst $\mathbf{3 c}$ is illustrative. ${ }^{36}$ The ether 89 without any substituent on the chain when treated with the catalyst $\mathbf{3 c}$ gives only the dimer whereas the diene 90 cyclises under identical condition to afford the cyclic ethers 91 in excellent yields (scheme 27).

This concept has been exploited for the synthesis of the key intermediates $\mathbf{9 3}$ and $\mathbf{9 5}$ in the total synthesis of the natural product laurencin through RCM of the dienes 92 and 94 respectively (scheme 28). ${ }^{37}$

The nine-membered oxacycle 97 is formed by RCM of the diene 96 in excellent yield (scheme 29).

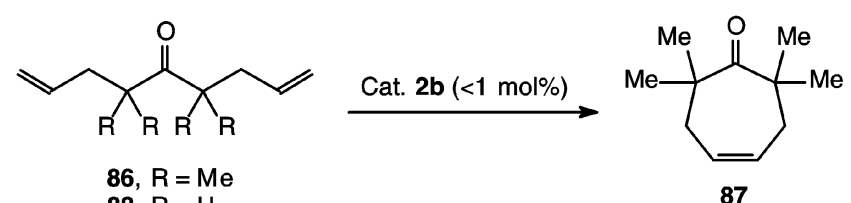

Scheme 26.

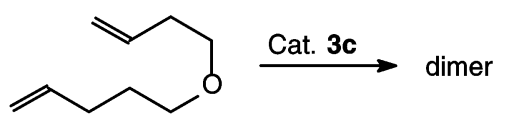

89<smiles>C=CCCOC[C@@H](COC(C)=O)[C@@H](C=C)OC(C)=O</smiles>

Scheme 27.

Scheme 25. 
The facile formation of $\mathbf{9 7}$ from $\mathbf{9 6}$ is probably the outcome of two synergistic gauch effects provided by a pair of vicinal substituents on the diene. ${ }^{38}$

Sometimes the steric effect present in the compound acts as an acyclic conformational constraint. The diene 98 when treated with the catalyst $\mathbf{3 b}$ undergoes RCM to form the aza cyclooctene 99 in very good yield (scheme 30). ${ }^{39}$ The tosyl group, due to its steric bulk, restricts the conformational flexibility of the terminal alkene units and facilitates ring closure.

The steric effect of a bulky substituent on acyclic diene can restrict the conformational freedom, forcing the alkenes to undergo ring closure during RCM, as has been demonstrated by Linderman. ${ }^{40}$ The diene 100a with a tributyl stannyl group on the diene undergoes smooth ring closure with Grubbs' catalyst 3c to form the oxocane 101 (scheme 31). When the tributyl stannyl group is replaced by a $t$-Bu group, the diene 100b undergoes polymerisation under similar conditions. This has been attributed to the larger size of the tributyl stannyl group as compared
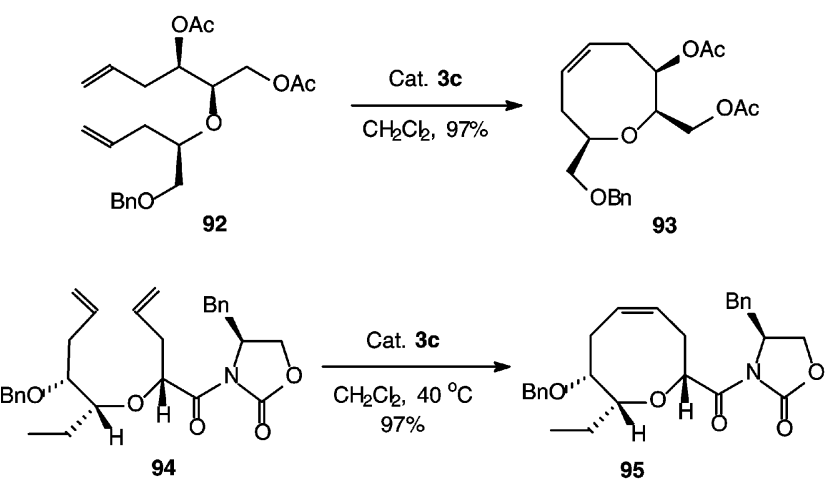

Scheme 28.

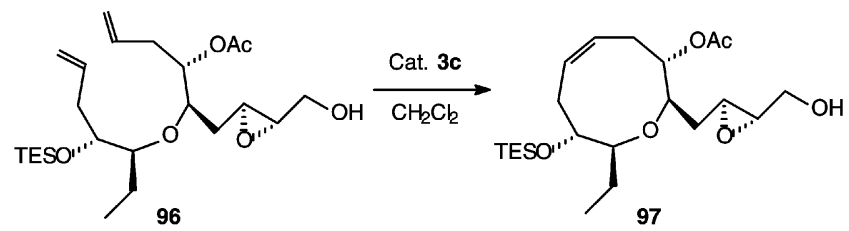

Scheme 29.

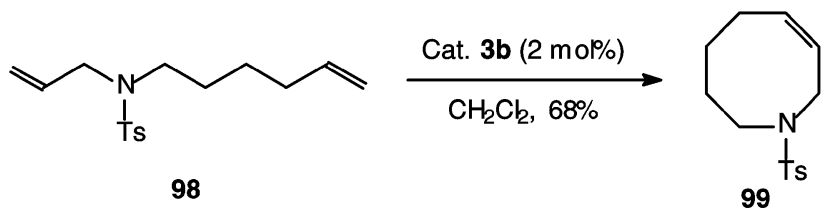

to the $t$-Bu group. Another reason for enhanced reactivity of the diene 100a is possibly the result of a unique stereoelectronic effect due to the interaction between $\mathrm{Sn}$ and $\mathrm{O}$ atoms or the $\mathrm{Sn}$ and $\mathrm{Ru}$ carbene complex.

\subsection{Synthesis of macrocycles}

The majority of investigations leading to macrocyclization are aimed at the synthesis of macrocyclic lactones as a number of naturally occurring macrocyclic lactones exhibit significant biological activity. Unlike formation of medium rings by RCM, a suitably biased conformation is generally not required for macrocyclization. However, to reduce the rate of the key competing reaction, oligomerization, during macrocycle formation, a low concentration of the diene with higher temperature and higher catalyst loading is necessary. Thus, cyclization of the highly flexible diene $\mathbf{1 0 2}$ with the catalyst $\mathbf{3 b}$ under slow addition affords the 16-membered lactone $\mathbf{1 0 3}$ (scheme 32)..$^{41 a}$

For efficient synthesis of macrocyclic lactones, a well-balanced interaction of Lewis-basic heteroatoms of the diene substrate with the emerging Lewis-acidic carbene intermediates is important. In the absence of any heteroatoms that lead to such interaction, macrocyclization fails as illustrated by failure of the diene $\mathbf{1 0 4}$ to undergo cyclisation ${ }^{4 \mathrm{~b}}$ with $4 \mathrm{~mol} \%$ of the catalyst $\mathbf{3 b}$ under high dilution.

If such interaction becomes too strong as in the case of the diene 105, the activity of the metal car-

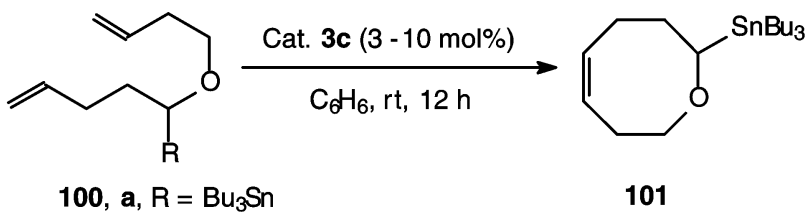

Scheme 31 .

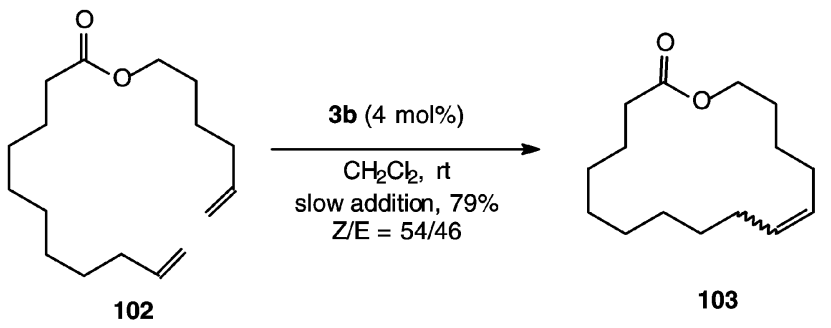

Scheme 32.

Scheme 30. 
bene decreases due to chelation as shown in structure 106 and RCM does not take place. ${ }^{41 \mathrm{~b}}$ The diene 107, where such chelation is weak or absent, undergoes smooth ring closure to form the macrocycle $\mathbf{1 0 8}$ (scheme 33). ${ }^{41 \mathrm{~b}}$

Formation of highly strained macrocycles, however, requires preexisting conformational constraints. In an attempt to construct the macrocyclic ring present in roseophilin, attempted RCM of the diene 109a fails to produce the macrocycle 110a even under high dilution. However, a triisopropylsiloxy group on the chain as a conformational control element as in the diene $\mathbf{1 0 9 b}$, forces the alkene side chains to come into closer proximity and cyclization occurs smoothly (scheme 34$){ }^{42}$

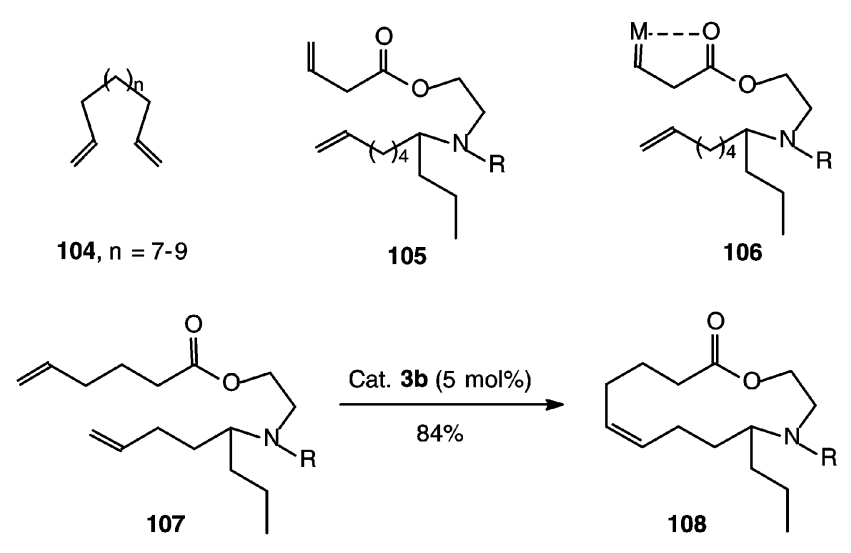

Scheme 33.

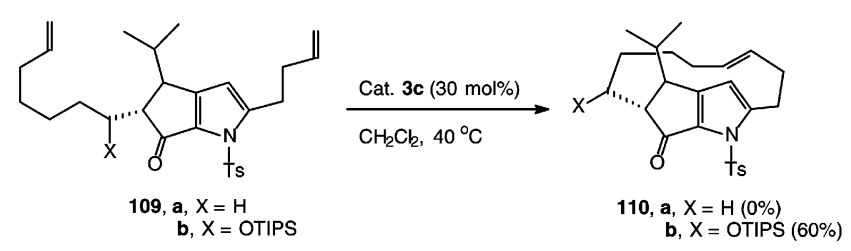

Scheme 34.
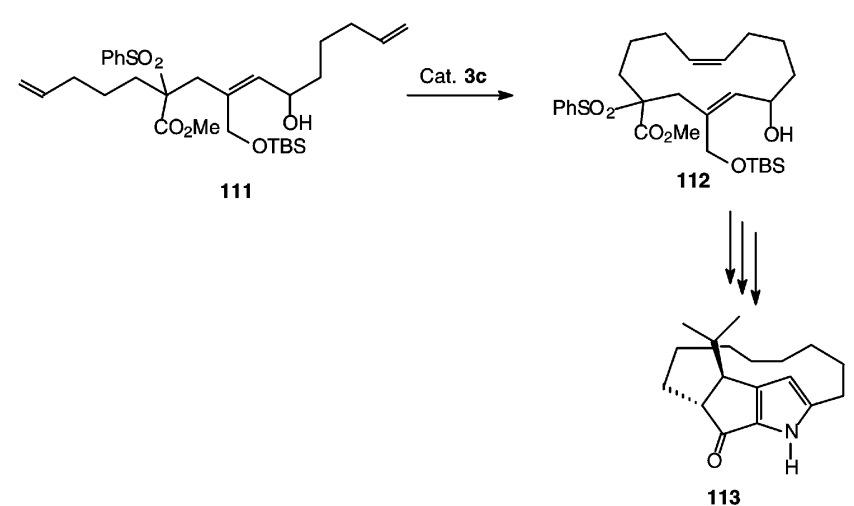

Scheme 35.
In contrast, the triene $\mathbf{1 1 1}$ lacking the ketopyrrole unit is free of strain as present in the diene 109a. No additional conformational control element is required for its cyclisation. Thus it can be smoothly cycli$\operatorname{sed}^{43}$ with the catalyst $3 \mathbf{c}$ to form the appropriately functionalised thirteen-membered ring 112 present in roseophilin. The ketopyrrole unit is then constructed (scheme 35 ) on this macrocycle for elaboration to roseophilin.

The efficiency of RCM in forming macrocycle has been demonstrated by the construction of the 16membered macrocyclic lactones by several research groups in approaches to the anticancer compound, epothiolone. For example, RCM of the diene 114 is accomplished in dilute $\mathrm{CH}_{2} \mathrm{Cl}_{2}$ solution with the catalyst 3c (scheme 36). ${ }^{44}$

Conformational preorganization facilitates macrocycle formation by RCM as has been nicely demonstrated by Iqbal and co-workers ${ }^{45}$ in their studies involving $\beta$-turn mimics. The tripeptide 116 preorganises itself leading to a $\beta$-turn. Thus, the diene 116 when subjected to RCM in the presence of catalyst 3c undergoes smooth ring closure to form the cyclic peptide 117 in very good yield (scheme 37 ).

\section{Effect of allylic substituents on RCM}

Substituent at the allylic position of a substrate greatly influences RCM reactivity. An alkyl substitution at the allylic position retards the reaction of the alkene with metal carbene. Ulman and Grubbs ${ }^{46}$ reported that $t$-butylethylene, containing a fully substituted allylic centre, is inert to reaction with the catalyst 3c. In contrast, a hydroxyl group at the allylic position has an accelerating effect on RCM. A systematic investigation by Hoye and $\mathrm{Zhao}^{47}$ (scheme 38) nicely demonstrates the effect of alkyl and hydroxyl substitution on RCM of the dienes 118a-e. One of the alkene units in these substrates is trisubstituted so that metathesis is initiated at the terminal alkene.

It is observed that on going from 118a to 118e, RCM reactivity increases. The diene 118a in which the allylic carbon is fully substituted is almost inert to ring closure while the diene $\mathbf{1 1 8 d}$ having a tertiary hydroxyl group at the allylic position has a significant activating effect on the reaction rate. The diene 118e having a secondary hydroxyl group being less sterically crowded than $\mathbf{1 1 8 d}$ is found to be most reactive, illustrating the activating effect of the hydroxyl group on RCM. This effect of the hydroxyl group may possibly arise through preassociation of 


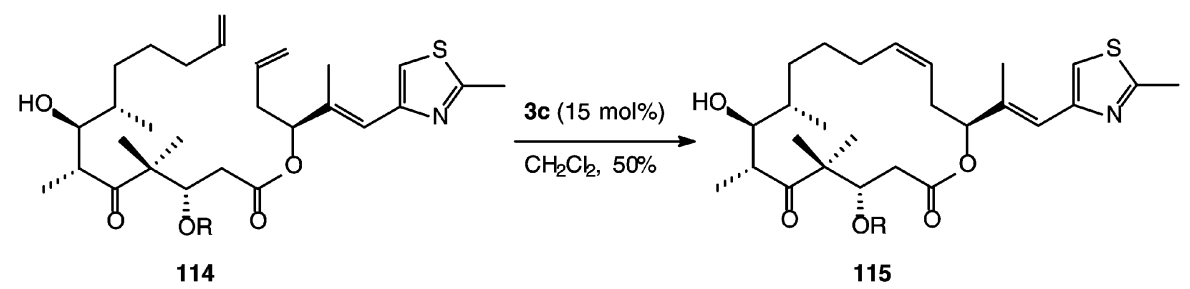

Scheme 36.

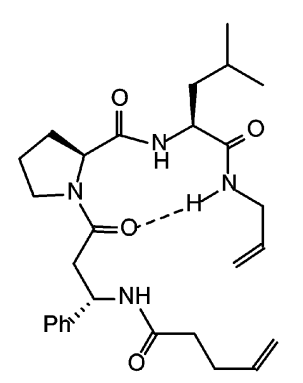

116

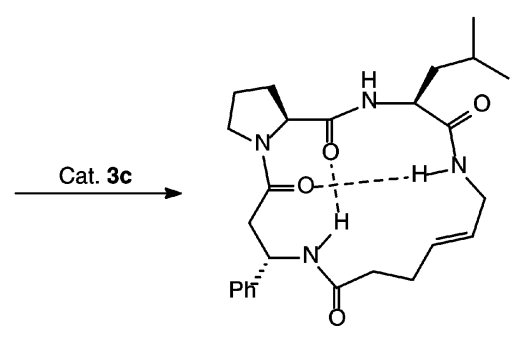

117

Scheme 37.

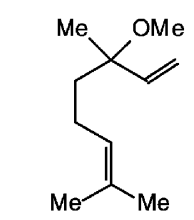

$(0)^{\star}$

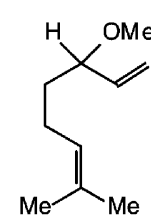

(1)<smiles>C=CC(C)CCC=C(C)C</smiles>

(8)

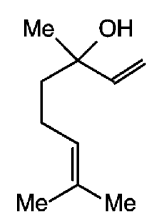

(12)

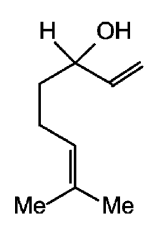

(60)

118 a

b

c

d

*Numbers in parentheses show approximate relative reactivities<smiles>C=CC(O)CCC=C(C)C</smiles><smiles>C=CCCCC(O)C=[14CH2]</smiles>

Scheme 38.

the diene with the catalyst by forming one of the species: $(\mathrm{RO}) \mathrm{Cl}\left(\mathrm{Cy}_{3} \mathrm{P}\right)_{2} \mathrm{Ru}=\mathrm{CHPh}, \mathrm{Cl}_{2}\left(\mathrm{Cy}_{3} \mathrm{P}\right)(\mathrm{ROH})$ $\mathrm{Ru}=\mathrm{CHPh}$ or $\left[\mathrm{Cl}_{2}\left(\mathrm{Cy}_{3} \mathrm{P}\right)(\mathrm{RO}) \mathrm{Ru}=\mathrm{CHPh}\right]^{-}\left[\mathrm{Cy}_{3} \mathrm{PH}\right]^{+}$. Hydrogen bonding between the hydroxyl group and one of the chloride ligands may also favour reaction between the alkene and carbene centre.

In spite of the large activating effect of allylic hydroxyl group, a competing reaction during RCM of 


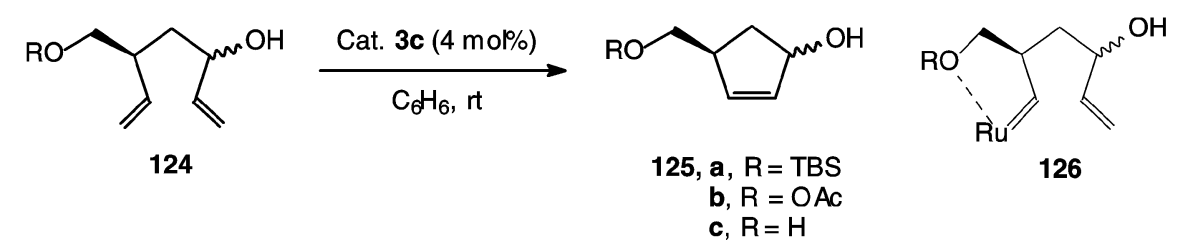

Scheme 39.

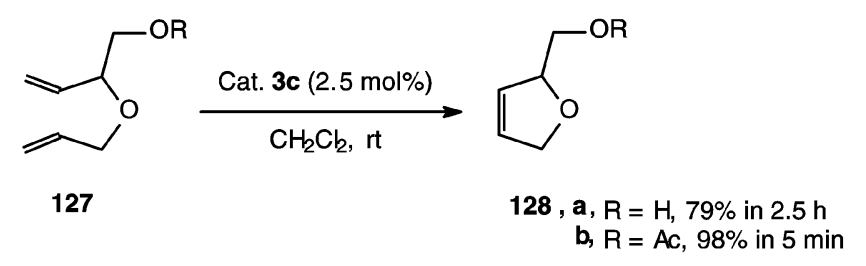

Scheme 40.

the diene 118e leads to the formation of the methyl ketone $\mathbf{1 2 0}$ in addition to the RCM product $\mathbf{1 1 9}$ in $1: 1.5$ ratio. Tautomerisation of the initially formed carbene 121 to the enolyl ruthenium hydride species 122 followed by reductive elimination to the oxoalkyl ruthenium 123 (scheme 38) has been suggested as the reason for formation of the methyl ketone. Similar observation on RCM of the diene containing secondary allylic hydroxyl group has been reported by others ${ }^{17}$ also.

In contrast to the above observation, we recently observed $^{48}$ that RCM of the dienes 124a,b having a secondary hydroxyl group at the allylic position, occurs smoothly with the catalyst $\mathbf{3 c}$ to produce only the cyclopentenols 125a,b in $93 \%$ and $79 \%$ yields respectively, while the diene $\mathbf{1 2 4 c}$ produces only oligomers.

It is noteworthy that the dienes $\mathbf{1 2 4 a}, \mathbf{b}$ and $\mathbf{c}$ contain a hydroxyl group at one of the allylic carbons and an alkyl group at the other allylic carbon, both of which deter RCM (scheme 39). The dramatic increase in reactivity of the dienols 124a and 124b may be attributed to the stabilization of the initially formed Ru-carbene $\mathbf{1 2 6}$ by the oxygen atom present in the allylic alkyl substituent. This stabilization probably directs metathesis initiation at the alkene nearest to the alkoxy group and thus overrides the competitive fragmentation due to the allylic secondary hydroxyl group. The bulkier alkoxy or acetoxy groups in $\mathbf{1 2 4 a}$ and $\mathbf{1 2 4 b}$ respectively facilitate dissociation of the oxygen atom from the stabilized $\mathrm{Ru}$ carbene $\mathbf{1 2 6}$ required for subsequent reaction with the second alkene unit. This also explains the lack of RCM reactivity of the dienol $\mathbf{1 2 4 c}$.
Significant rate acceleration in RCM of diene $\mathbf{1 2 7}$ having a acetoxy group (scheme 40) over that of the diene 127 with a hydroxyl group has been observed by Sarkar and co-workers. ${ }^{49}$ Thus, RCM of the diene 127a with the catalyst $3 \mathrm{c}$ takes $2.5 \mathrm{~h}$ to produce the cyclopentene 128a while RCM of the diene 127b with the catalyst $\mathbf{3 c}$ is complete within $5 \mathrm{~min}$.

\section{Conclusion}

Key features that determine the success of ring closure reactions through olefin metathesis have been summarized with illustrative examples. The catalyst plays a major role in the success of a ring closure reaction. Ring closure of substrates containing highly substituted olefin requires the use of Schrock's catalyst 2b or Grubbs' catalyst 9. Six-membered rings are the most easily accessible compared to five- and seven-membered rings. For synthesis of mediumsized rings, pre-organization of the substrates is essential. Macrocyclization requires lower substrate concentration with high catalyst loading. Preorganisation of the substrates is not always required. Allylic substituents also play an important role. Thus this account provides some guidelines for designing synthesis of cyclic structures.

\section{Acknowledgement}

Financial support from the Department of Science and Technology, Govt. of India is gratefully acknowledged. NS wishes to thank the Council of Scientific and Industrial Research, New Delhi for a fellowship.

\section{References}

1. Herisson J-L and Chauvin Y 1971 Makromol. Chem. 141161

2. (a) Schuster M and Blechert S 1997 Angew. Chem. Int. Ed. 36 2036; (b) Grubbs R H and Chang S 1998 Tetrahedron 54 4413; (c) Furstner A 2000 Angew. Chem. Int. Ed. 39 3012; (d) Maier M E 2000 Angew. 
Chem. Int. Ed. 39 2073; (e) Armstrong S K 1998 J. Chem. Soc. Perkin Trans. 1 371; (f) Kotha S and Sreenivasachary N 2001 Indian J. Chem. B40 763; (g) Dieters A and Martin S F 2004 Chem. Rev. 104 2199; (h) Nicolaou K C, Bulger P G and Sarlah D 2005 Angew. Chem. Int. Ed. 444490

3. For excellent accounts on design and development of olefin metathesis catalysts see: (a) Pariya C, Jayaprakash K N and Sarkar A 1998 Coord. Chem. Rev. 168 1; (b) Trnka T M and Grubbs R H 2001 Acc. Chem. Res. 34 18; (c) Grubbs R H 2004 Tetrahedron 607117

4. (a) Fu G C and Grubbs R H 1992 J. Am. Chem. Soc. 114 5426; (b) Fu G C and Grubbs R H 1992 J. Am. Chem. Soc. 114 7324; (c) Fu G C and Grubbs R H 1993 J. Am. Chem. Soc. 1153800

5. Dias E L, Nguyen S T and Grubbs R H 1997 J. Am. Chem. Soc. 1193887

6. Kirkland T A and Grubbs R H 1997 J. Org. Chem. 62 7310

7. Sita L R 1995 Macromolecules 28656

8. Shon Y-S and Lee T R 1997 Tetrahedron Lett. 38 1283

9. (a) Clark J S and Kettle J G 1997 Tetrahedron Lett. 38 123; (b) Fujimura O, Fu G C and Grubbs R H 1994 J. Org. Chem. 594029

10. Sturino C F and Wong J C Y 1998 Tetrahedron Lett. 399628

11. Furstner A and Langermann K 1996 J. Org. Chem. 61 8746

12. Ackermann I, Tom D E and Furstner A 2000 Tetrahedron $\mathbf{5 6} 2196$

13. Holder S and Blechert S 1996 Synlett 505

14. Sabui S K and Venkateswaran R V 2004 Tetrahedron Lett. 452047

15. Bhaumik T and Ghosh S (unpublished work)

16. Overkleeft H S and Pandit U K 1996 Tetrahedron Lett. 37547

17. Paquette L A and Efremov I $2001 \mathrm{~J}$. Am. Chem. Soc. 1234492

18. Huwe C M and Blechert S 1997 Synthesis 61

19. Baylon C, Heck M P and Mioskowski C 1999 J. Org. Chem. 643354

20. Heck M P, Baylon C, Nolan S P and Mioskowski C 2001 Organic Lett. 31989

21. (a) Dieltiens N, Stevens C V, Vos D D, Allaert B, Drozdzak R and Verpoort F 2004 Tetrahedron Lett. 200445 8995; (b) Clercq B D and Verpoort F 2001 Tetrahedron Lett. 42 8959; (c) Briot A, Bujard M, Gouverneur V, Nolan S P and Mioskowski C 2000 Org. Lett. 2 1517; (d) Furstner A, Thiel O R, Ackermann L, Sehang H-J and Nolan S P 2000 J. Org. Chem. 652204

22. Fu G C, Nguyen S T and Grubbs R H 1993 J. Am. Chem. Soc. 1159856

23. Yang Q, Xiao W J and Yu Z 2005 Org. Lett. 7871

24. Engler E M, Andose J D and Schleyer P von R 1973 J. Am. Chem. Soc. 958005
25. Kahnberg $\mathrm{P}$, Lee $\mathrm{C} \mathrm{W}$, Grubbs $\mathrm{R} \mathrm{H}$ and Sterner $\mathrm{O}$ 2002 Tetrahedron 285203

26. Clark J S and Kettle J G 1997 Tetrahedron Lett. 38 127

27. Holt D J, Barker W D, Jenkins P R, Panda J and Ghosh S 2000 J. Org. Chem. 65482

28. (a) Mehta G and Umarye J D 2002 Org. Lett. 4 1063; (b) Srikrishna A and Dethe D H 2004 Org. Lett. 6 165

29. Miller S J, Kim S-H, Chen Z-R and Grubbs R H 1995 J. Am. Chem. Soc. 1172108

30. Holt D J, Barker W D, Jenkins P R, Davies D L, Garratt S, Fawcett J, Russel D R and Ghosh S 1998 Angew. Chem. Int. Ed. 373298

31. Bourgeois D, Pancrazi A, Ricard L and Prunet J 2000 Angew. Chem. Int. Ed. 39726

32. (a) Diedrichs N and Westermann B 1999 Synlett 1127; (b) Tarling C A, Holmes A B, Markwell R E and Pearson N D 1999 J. Chem. Soc. Perkin Trans. 11695

33. Grossmith C E, Senia F and Wagner J 1999 Synlett 1660

34. Cook G R, Shanker P S and Peterson S L 1999 Org. Lett. 1615

35. Forbes M D E, Patton J T, Mayers T L, Maynard H D, Smith D W Jr., Schulz G R and Wagener K B 1992 J. Am. Chem. Soc. 11410978

36. (a) Crimmins M T and Choy A L $1999 \mathrm{~J}$. Am. Chem. Soc. 121 5653; (b) Edwards S D, Lewis T and Taylor R J K 1999 Tetrahedron Lett. 404267

37. Crimmins M T and Emmitte K A 1999 Org. Lett. 1 2029

38. (a) Crimmins M T, Emmitte K A and Choy A L 2002 Tetrahedron 58 1817; (b) Crimmins M T and Emmitte K A 2001 J. Am. Chem. Soc. 1231533

39. Miller S J, Kim S-H, Chen Z-R and Grubbs R H 1995 J. Am. Chem. Soc. 1172108

40. Linderman R J, Siedlecki J, O'Neil S A and Sum H 1997 J. Am. Chem. Soc. 1196919

41. (a) Furstner A and Langermann K 1996 J. Org. Chem. 61 3942; (b) Furstner A and Langemann K 1997 Synthesis 792

42. Kim S H, Figueroa I and Fuchs P L 1997 Tetrahedron Lett. 382601

43. Furstner A, Gastner T and Weintritt H 1999 J. Org. Chem. 642361

44. (a) Nicolaou K C, He Y, Vourloumis D, Vallberg H and Yang Z 1996 Angew. Chem. Int. Ed. 35 2399; (b) Yang Z, He Y, Vourloumis D, Vallberg H and Nicolaou K C 1997 Angew. Chem. Int. Ed. 36166

45. Banerji B, Mallesham B, Kumar S K, Kunwar A C and Iqbal J 2002 Tetrahedron Lett. 436479

46. Ulman M and Grubbs R H 1998 Organometallics 17 2484

47. Hoye T R and Zhao H 1999 Org. Lett. 11123

48. Nayek A, Banerjee S, Sinha S and Ghosh S 2004 Tetrahedron Lett. 456457

49. Maishal T K, Sinha-Mahapatra D K, Paranjape K and Sarkar A 2002 Tetrahedron Lett. 432263 